\title{
Caustic Waste-Soil Weathering Reactions and Their Impacts on Trace Contaminant Migration and Sequestration
}

\author{
Jon D. Chorover \\ Department of Soil, Water \\ and Environmental Sciences \\ Shantz 429, Building \#38 \\ University of Arizona \\ Tucson, AZ 85721-0038
}

\begin{abstract}
We are studying Cs, Sr and I uptake and release during clay mineral weathering under conditions representative of caustic tank waste leachate. Cesium sorption after 1 year reaction was the greatest in the order of vermiculite, illte, montmorillonite and kaolinite. Vermiculite showed highest Sr sorption, followed by kaolinite, montmorillonite and illite. Secondary phase products were feldspathoid sodium aluminum nitrate silicate, sodium aluminum nitrate silicate hydrate, Na-Al chabazite and zeolite X. Discrete Sr phases were found in kaolinite and illite systems after at 10-3 M Cs/Sr. Transmission electron microscopy with EDS indicates a high single Sr phase in illite systems. Spheroidal secondary phases are common in all clay consisting of intergrown Na-containing sodalite and cancrinite. In the case of illite, montmorillonite and kaolinite, Cs or Sr are found in association with these neoformed spheroidal secondary phases, but this is not the case in vermiculite systems. In vermiculite, most of Cs and $\mathrm{Sr}$ is associated with clay particle, presumably because of its high charge density, rather than secondary phases. For detailed investigations of $\mathrm{Cs} / \mathrm{Sr}$ coprecipitation with neoformed alumosilicate during the clay weathering process, we are conducting homogeneous nucleation experiments in the absence of clay minerals. Silica is reacted with synthetic tank waste to elucidate sites of $\mathrm{Cs}$, Sr and I uptake in products. We are varying the $\mathrm{Si} / \mathrm{Al}$ and the initial $\mathrm{Cs}, \mathrm{Sr}$ and I concentrations to examine effects on mineral formation and uptake rate. To date, we have observed that precipitation kinetics and the nature of reaction products varies with initial Cs, Sr and I concentration. Solid phase products are being investigated by XRD, FTIR, NMR and EXAFS, and are also being subjected to dissolution kinetics studies to assess long term stability.
\end{abstract}

